\title{
Cystatin F Affects Natural Killer Cell Cytotoxicity
}

\author{
Milica Perišić Nanut', Jerica Sabotič', Urban Švajger ${ }^{2}$, Anahid Jewett ${ }^{3}$ and Janko Kos ${ }^{1,4 *}$ \\ ${ }^{1}$ Department of Biotechnology, Jožef Stefan Institute, Ljubljana, Slovenia, ${ }^{2}$ Blood Transfusion Center, Ljubljana, Slovenia, \\ ${ }^{3}$ The Jane and Jerry Weintraub Center for Reconstructive Biotechnology, Division of Oral Biology and Medicine, UCLA \\ School of Dentistry, University of California-Los Angeles, Los Angeles, CA, United States, ${ }^{4}$ Faculty of Pharmacy, University of \\ Ljubljana, Ljubljana, Slovenia
}

Cystatin $\mathrm{F}$ is a cysteine peptidase inhibitor which, unlike other cystatin family members, is targeted to endosomal/lysosomal compartments. It is synthesized as an inactive disulfide-linked dimer which is then converted to an active monomer by proteolytic cleavage of $15 \mathrm{~N}$-terminal residues. Cystatin $\mathrm{F}$ has been suggested to regulate the cytotoxicity of natural killer (NK) cells by inhibiting the major granzyme convertases, cathepsins $\mathrm{C}$ and $\mathrm{H}$. To test this hypothesis, we prepared variants of cystatin $\mathrm{F}$ and analyzed their uptake, subcellular trafficking, and peptidase inhibition, as well as their impact on the cytotoxicity of NK-92 cells and primary NK cells. The N-glycosylation pattern is responsible for the secretion, uptake, and subcellular sorting of cystatin $\mathrm{F}$ in

OPEN ACCESS

Edited by:

Fabrizio Mattei,

Istituto Superiore di Sanità, Italy

Reviewed by: George P. Munson, University of Miami, United States Alessandro Poggi,

Azienda Ospedaliera Universitaria San Martino (IRCCS), Italy

${ }^{*}$ Correspondence: Janko Kos janko.kos@ffa.uni-lj.si

Specialty section: This article was submitted to Cancer Immunity and Immunotherapy,

a section of the journal

Frontiers in Immunology

Received: 27 July 2017 Accepted: 18 October 2017 Published: 13 November 2017

Citation:

Perišić Nanut M, SabotičJ, Švajger U, Jewett $A$ and Kos J (2017)

Cystatin F Affects Natural Killer Cell Cytotoxicity.

Front. Immunol. 8:1459. doi: 10.3389/fimmu.2017.01459
HeLa and Hek293 cells, whereas the legumain binding site had no effect on these processes. Active, N-terminally truncated, monomeric cystatin $\mathrm{F}$ can also be internalized by recipient cells and targeted to endo/lysosomes, affecting also cells lacking the activating peptidase. Cystatin F mutants capable of cell internalization and trafficking through the endo/lysosomal pathway significantly decreased cathepsin $\mathrm{C}$ and $\mathrm{H}$ activities, both in situ, following transfection and in trans, using conditioned media. Further, incubation of IL-2 stimulated NK-92 and primary NK cells with full-length and N-terminally truncated cystatin $\mathrm{F}$ mutants led to suppression of their granule-mediated cytotoxicity. This effect was most significant with the $\mathrm{N}$-terminally truncated mutants. These results suggest that cystatin $\mathrm{F}$ can be an important mediator within tumor microenvironment affecting the cytotoxicity of NK cells and consequently antitumor immune response.

Keywords: cytotoxic cells, cystatin F, granule-mediated cytotoxicity, cathepsin C, granzyme B

\section{INTRODUCTION}

Natural killer (NK) cells are effector cells of innate immunity that play an important role in cancer immunosurveillance (1) as well as in controlling tumor growth and progression. However, functional impairments of NK cells have frequently been reported in cancer patients (2), so that understanding the complex mechanisms of the inactivation of NK cells could be of great importance for improving NK cell-based immunotherapy of cancer (3).

Although NK cells can utilize various mechanisms to eliminate target cells, granule-mediated cytotoxicity, involving the pore-forming protein, perforin, and the serine peptidases granzymes, granzymes A and B, appears to be the primary one that NK cells employ toward cancer cells $(4,5)$. Besides granzymes, lysosomal cysteine peptidases also play an important role in granule-mediated cytotoxicity $(6,7)$. Granzymes are synthesized as inactive pro-granzymes, which are proteolytically 
activated on reaching the secretory lysosomes (6-8). Cathepsin $\mathrm{C}$ is considered to be the main peptidase that is able to generate active granzyme $\mathrm{B}$, whereas cathepsin $\mathrm{H}$ serves as an alternative one that generates active granzyme $\mathrm{B}$ in the absence of cathepsin $\mathrm{C}$ (9). Similarly, the precursor form of perforin is cleaved proteolytically by cathepsin L (10). Finally, asparaginyl endopeptidase, also known as legumain, that shares a basic mechanism of action and localization to the endo/lysosomes with lysosomal cysteine peptidases, has also been implicated in the cytotoxicity of NK cells (11).

Major regulators of cysteine peptidases are their endogenous protein inhibitors, cystatins. The majority of these reversible and tight-binding peptidase inhibitors act extracellularly, controlling secreted or misdirected peptidases $(12,13)$. Cystatin F, a member of the type II cystatin family, is an exception, since it acts predominantly intracellularly. When synthesized, it dimerizes through two disulfide bridges involving Cys26 on one subunit and Cys63 on the other (Figure 1), rendering the molecule inactive as an inhibitor of cysteine cathepsins $(14,15)$. Cystatin $\mathrm{F}$ is redirected by several $\mathrm{N}$-linked glycans from the secretory pathway via mannose-6-phosphate receptors (M6P) toward endo/ lysosomal compartments $(16,17)$ where it is activated through monomerization. Some of the cystatin F is also secreted as an inactive dimer which can be internalized by, and activated inside recipient cells (18).

The inhibitory profile of cystatin $\mathrm{F}$ is dependent on its molecular form. Its disulfide-linked dimer does not inhibit the C1 family of cysteine proteases. In vitro, unusually strong reducing conditions are needed to dissociate the dimer (19). However, proteolytic cleavage of the $15 \mathrm{~N}$-terminal amino acids (AA) significantly enhances the monomerization and also alters the inhibitory properties of the resulting monomer (20). Intact monomeric cystatin $\mathrm{F}$ binds tightly to cysteine endopeptidases, such as cathepsins L, F, K, and V, less tightly to cathepsins S and $\mathrm{H}$, but not at all to the exopeptidases cathepsins B, X, and C (19). Cystatin $\mathrm{F}$, following $\mathrm{N}$-terminal truncation, becomes a strong inhibitor of cathepsin $\mathrm{C}$, whereas its ability to inhibit cathepsin $\mathrm{H}$ is only slightly increased $(20,21)$. Moreover, cystatin $\mathrm{F}$, in both monomeric and dimeric forms, inhibits the C13 family endopeptidase, legumain, through a distant second binding site (Figure 1) (22). Cystatin F is expressed in immune cells such as cytotoxic lymphocytes, eosinophils, neutrophils, and mast cells, as well as in dendritic cells and macrophages, most probably being involved in processes of the immune response (23-28). In dendritic cells, it is probable that cystatin $\mathrm{F}$ regulates the activity of cathepsin L, thus controlling the processing of procathepsin X, which promotes cell adhesion (21). Cystatin F is also implicated in several pathological processes. It has been suggested to play a role in multiple sclerosis during the acute phase of demyelination $(29,30)$, in polycythemia vera, a myeloproliferative disorder characterized by an increased proliferation of cells of myeloid lineages (31) and in chronic fatigue syndrome (32). Higher expression of the inhibitor correlates with the inflammatory processes associated with lung disorders (33). Increased cystatin F has also been detected in some tumors, correlating with their higher metastatic potential (34). Its overexpression and secretion was also confirmed in human cancer cell lines and patient-derived metastatic cells $(34,35)$. In contrast to the majority of other type II cystatins which are generally downregulated in tumors (25), cystatin F was found to be markedly upregulated in tumors of colorectal cancer patients compared to the corresponding non-tumor tissue, correlating with higher frequency of liver metastasis (36). Within the tumor microenvironment besides tumor cells several other cell types, including immune cells could be a source of increased level of cystatin F (37).

Finally, as a potent inhibitor of the pro-granzyme convertases, cathepsins $\mathrm{C}$ and $\mathrm{H}$, cystatin $\mathrm{F}$ was suggested to be a regulator of the cytotoxicity of CD8+ lymphocytes and NK cells $(16,38)$.

In a recent study, we demonstrated that increased levels of cystatin $\mathrm{F}$ and decreased levels of cathepsins $\mathrm{C}$ and $\mathrm{H}$ are associated with target-induced inactivation of NK cell cytotoxicity, termed split anergy (38). This phenomenon, coupled with increased cytokine secretion and lower cytotoxicity of NK cells, can be triggered by tumor cells, monocytes or anti-CD16 antibodies. The result is decreased activation of pro-granzymes and, consequently, lower cytotoxicity, which coincides with higher concentrations of monomeric cystatin F (38-40). The aim of the present study was thus to demonstrate that cystatin $\mathrm{F}$, originating from target cells, regulates in trans the cytotoxicity of NK cells. As an inactive dimer, secreted cystatin $\mathrm{F}$ is not sequestered by extracellular peptidases but is internalized by recipient cells and activated
A

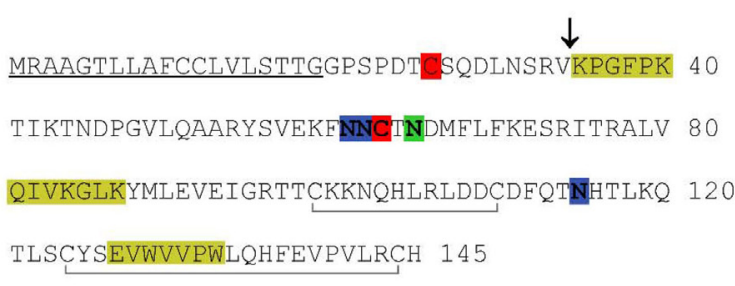

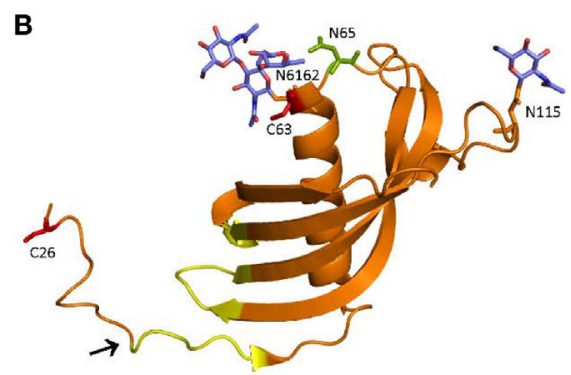

FIGURE 1 | Amino acid (AA) sequence (A) and ribbon diagram (B) of human cystatin F. In the AA sequence, the signal peptide is underlined, the probable region of cysteine cathepsin interaction is highlighted in yellow, the legumain (asparaginyl endopeptidase) interaction site in green, the N-linked glycosylation sites in blue, the cysteines involved in dimerization in red, and the internal disulfide bonds indicated with gray lines below the sequence (A). In the ribbon diagram (PDB 2CH9), the probable region of cysteine cathepsin interaction is indicated in yellow. The legumain interaction site (green), cysteines involved in dimerization (red) and $\mathrm{N}$-linked glycans (blue) are shown as stick models (B). The N-terminal truncation site is indicated with an arrow in both panels. 
within endosomal/lysosomal vesicles. By using various mutants of cystatin F (Table 1), we analyzed the dimerization, intracellular sorting/trafficking, and peptidase inhibition, together with their impact on the cytotoxicity of NK cells. Our results point to a new mechanism, which could be used by tumor cells to escape the antitumor immune response, and suggest possible targets for improving cancer immunotherapy.

\section{MATERIALS AND METHODS}

\section{Cell Culture}

Hek293 (ATCC: CRL-1573), HeLa (ATCC: CCL-2), and MCF-7 (ATCC: HTB-22) cells were maintained in DMEM media supplemented with $10 \%$ fetal bovine serum (10270-106, Gibco). K562 (ATCC: CCL-243) cells were grown in RPMI 1640 culture medium (12-115F/12, Lonza) supplemented with $10 \%$ heat inactivated fetal bovine serum (hiFBS) (10500-064, Gibco). The human IL-2-dependent NK-92 cells (ATCC: CRL-2407) were maintained in RPMI 1640 culture medium, supplemented with $12.5 \%$ hiFBS, $12.5 \%$ Heat Inactivated Horse Serum (Gibco, 26050088), and $100 \mathrm{U} / \mathrm{mL}$ rhIL-2 (H-7365.0050, Bachem). NK-92 can be genetically altered to target specific tumor antigens and express activating receptors, thereby increasing their cytotoxicity and potential for use in immunotherapy (41). All cell culture media contained $100 \mathrm{U} / \mathrm{mL}$ penicillin and $0.1 \mathrm{mg} /$ $\mathrm{mL}$ streptomycin (15140122, Gibco). Suspension freestyle Hek293F cells (K900001, Thermo Fisher Scientific) were grown in FreeStyle Hek293 Expression Medium (12338018, Thermo Fisher Scientific). Apart from FreeStyle Hek293, which were grown in a humidified $37^{\circ} \mathrm{C}$ incubator on constant rotation and under $8 \% \mathrm{CO}_{2}$, the rest of cell lines and primary NK cells were grown in a humidified $37^{\circ} \mathrm{C}$ incubator under $5 \% \mathrm{CO}_{2}$.

\section{Construction, Expression, and Purification of Mutant Forms of Cystatin F}

The cystatin F (CST7) coding sequence (starting at downstream genomic ATG codon) was amplified from a plasmid from EST library clone HU3_p983D111007D2 (ImaGenes, Berlin, Germany) using primers for ligation into vector pcDNA3 (Table 1; Table S1 in Supplementary Material). This sequence served as the basis for the design of mutagenic oligonucleotides (Table 1; Table S1 in Supplementary Material). The amplified fragment and the target plasmid were digested with Hind III (R3104M)/EcoRI (R3101M) for cloning into pcDNA3, and ligated using T4 DNA ligase (M0202L) all purchased from NewEnglandBiolabs. N-terminally truncated cystatin F, double unglycosylated mutant (N6162S) and cystatin F with mutated binding site for legumain (N65K) were generated in PCR site-directed mutagenesis using KOD Hot Start DNA Polymerase (71086-5, Novagen Inc), expression plasmid pcDNA3 with cystatin $\mathrm{F}$ sequence as template and different pairs of primers (Table 1; Table S1 in Supplementary Material). The DpnI endonuclease (ER1705, Fermentas) was used for digestion of the matrix sequence and recovery of the vectors containing mutated inserts (42). Double (N6162S) unglycosylated and non-glycosylated (N6162SN115Q) mutants were prepared similarly using single or double mutants as matrix DNA in mutagenic PCR. For protein expression in Hek293 FreeStyle cells, additional mutagenesis was performed to introduce a 5-histidine C-terminal tag (Table 1; Table S1 in Supplementary Material) and single, double, or triple mutants as matrix DNA.

The endotoxin free pcDNA3 plasmids, containing C-terminally 6-His tagged full-length (wild-type) and mutant species of cystatin F, were prepared using NucleoBond Xtra Midi EF kit (740422.50, Macherey-Nagel). Transient transfection of freestyle Hek293F cells was performed using $293 \mathrm{fectin}^{\mathrm{TM}}$ Transfection reagent (K900001, Thermo Fisher Scientific) and following the manufacturer's instructions. Transfected cells were grown for 1 week; the cells were then pelleted, the cell culture medium concentrated using Amicon ${ }^{\circledR}$ Ultra-15 Centrifugal Filter Unit with Ultrace ${ }^{\circledR}-3$ membrane (UFC900324, Merck Millipore) and used for protein purification. The $\mathrm{NaCl}$ concentration in samples was adjusted to $400 \mathrm{mM}$ and the medium was passed over TALON metal affinity resin (635502, Clontech Laboratories, Inc.) equilibrated with $50 \mathrm{mM}$ Tris, $400 \mathrm{mM} \mathrm{NaCl}$, $\mathrm{pH}$ 7.4. The resin was washed with $50 \mathrm{mM}$ Tris, $500 \mathrm{mM} \mathrm{NaCl}$, $10 \mathrm{mM}$ imidazole, $\mathrm{pH} 7.4$ and the proteins eluted with $50 \mathrm{mM}$ Tris, $120 \mathrm{mM} \mathrm{NaCl}, 400 \mathrm{mM}$ imidazole, $\mathrm{pH}$ 7.4. Eluates were concentrated using Amicon ${ }^{\circledR}$ Ultra-15 Centrifugal Filter Unit (UFC900324, Millipore), and the buffer exchanged to $20 \mathrm{mM}$ Bis-Tris $\mathrm{pH}$ 6.5. The recombinant proteins were further purified using ÄKTA FPLC system (GE Healthcare Lifesciences) controlled by Unicorn software version 5.11 (GE Healthcare, Piscataway, NY, USA). The Mono S HR 5/5 column (17-054701 , Pharmacia) was equilibrated with five column volumes (CV) of $20 \mathrm{mM}$ Bis-Tris pH 6.5 buffer prior to loading, washed after loading with $3 \mathrm{CV}$ of the same buffer, followed by $15 \mathrm{CV}$ of $0-1 \mathrm{M}$ $\mathrm{NaCl}$ linear gradient elution at $\mathrm{pH} 6.5$ in $20 \mathrm{mM}$ Bis-Tris. The resulting protein was immediately dialyzed against phosphate buffered saline (PBS) and concentrated using Amicon ${ }^{\circledR}$ Ultra15 Centrifugal Filter Unit. The purity of isolated recombinant proteins was verified by SDS-PAGE and Silver staining (Figure S3 in Supplementary Material).

\section{Transfection and Protein Uptake}

Western blot analysis of cystatin F and the inhibition of intracellular peptidases was performed on post-nuclear lysates of HeLa and Hek293 cells upon transfection with pcDNA3 containing different untagged cystatin $\mathrm{F}$ mutants and upon conditioning (exposure to cell culture medium from cells transfected with vector containing cystatin $\mathrm{F}$ mutants for $24 \mathrm{~h}$ ). Cells (HeLa and Hek293) were grown in tissue culture treated 6-well plates (protease assays) or 24-well plates (immunoblot analysis) and transfected with plasmids containing either wild type or mutant forms of cystatin F, using PolyJet DNA Transfection Reagent (SL100688, Sinangen), following manufacturer's instructions. Transfected cells were left in culture for $24 \mathrm{~h}$ after which the cystatin F-enriched medium was removed, centrifuged ( $5 \mathrm{~min}$, $500 \mathrm{~g}$ ) and added to non-transfected cells (conditioninginternalization assays) which were grown for an additional $24 \mathrm{~h}$ before analysis. Cells transfected with empty pcDNA3 vector and conditioned with medium from empty vector-control cells served as controls. 
TABLE 1 | Mutant forms of cystatin F, matrix DNA, and primer pairs that were used in mutagenesis.

\begin{tabular}{|c|c|c|c|}
\hline Cystatin F variants & Plasmid name and relevant features of mutants & Matrix DNA & Primer pairs \\
\hline Wild-type & $\begin{array}{l}\text { wt cystatin F with signal sequence starting at } \\
\text { downstream ATG }\end{array}$ & EST library clone HU3_p983D111007D2 & $\begin{array}{l}\text { cysF_upstream } \\
\text { cysF_downstream }\end{array}$ \\
\hline$\Delta \mathbf{N}$ & $\begin{array}{l}\text { pcDNA3 dNCysF } \\
\text { Cystatin F signal sequence starting at downstream } \\
\text { ATG and lacking the first } 15 \mathrm{~N} \text {-terminal residues } \\
\text { (N-terminally truncated) }\end{array}$ & $\begin{array}{l}\text { pcDNA3 cystatin F with signal sequence } \\
\text { starting at downstream ATG }\end{array}$ & $\begin{array}{l}\text { dNCysF-F } \\
\text { dNCysF-R }\end{array}$ \\
\hline$\Delta \mathrm{N}$ C63S & $\begin{array}{l}\text { pcDNA3 dN C63S CysF } \\
\text { N-terminally truncated with C63S mutation }\end{array}$ & pcDNA3 dNCysF & $\begin{array}{l}\text { dNCysF-F } \\
\text { dNCysF-R }\end{array}$ \\
\hline N6162S & $\begin{array}{l}\text { pcDNA3 N6162SCysF } \\
\text { Double N-linked glycosylation sequence mutant } \\
\text {-61 and } 62 \text { Asn residues altered to Ser }\end{array}$ & $\begin{array}{l}\text { pcDNA3 cystatin F with signal sequence } \\
\text { starting at downstream ATG }\end{array}$ & $\begin{array}{l}\text { cysF_N61-62S_F } \\
\text { cysF_N61-62S_R }\end{array}$ \\
\hline N6162S N115Q & $\begin{array}{l}\text { pcDNA3 N6162S N115QCysF } \\
\text { Triple N-linked glycosylation sequence mutant }\end{array}$ & pcDNA3 N6162SCysF & $\begin{array}{l}\text { CysF-N96Q } \\
\text { CysF-N96Qc }\end{array}$ \\
\hline N65K & $\begin{array}{l}\text { pcDNA3 N65K CysF } \\
\text { legumain binding sequence mutant }\end{array}$ & $\begin{array}{l}\text { pcDNA3 wt cystatin F with signal } \\
\text { sequence starting at downstream ATG }\end{array}$ & $\begin{array}{l}\text { CysF-N65K F } \\
\text { CysF-N96Q R }\end{array}$ \\
\hline N65K N6162S N115Q & $\begin{array}{l}\text { pcDNA3 N65K N6162S N115Q CysF } \\
\text { Triple N-linked glycosylation and legumain binding } \\
\text { sequence mutant }\end{array}$ & pcDNA3 N6162S N115QCysF & $\begin{array}{l}\text { CysF-N65K F } \\
\text { CysF-N96Q R }\end{array}$ \\
\hline$\Delta \mathrm{N} N 65 \mathrm{~K}$ & $\begin{array}{l}\text { PcDNA3 dN N65Q CysF } \\
\text { N-terminally truncated and legumain binding } \\
\text { sequence mutant }\end{array}$ & pcDNA3 dNCysF & $\begin{array}{l}\text { CysF-N65K F } \\
\text { CysF-N96Q R }\end{array}$ \\
\hline wt-His & $\begin{array}{l}\text { pcDNA3 WT CysF 5His } \\
\text { His-tagged wt cysF }\end{array}$ & pcDNA3 wt Cystatin F & $\begin{array}{l}\text { cysF-6H-pCDNA_F } \\
\text { cysF-6H-pCDNA_R }\end{array}$ \\
\hline $\begin{array}{l}\text { N6162S N115Q-N6162S N115Q } \\
\text { His }\end{array}$ & $\begin{array}{l}\text { pcDNA3.1 N6162S N115Q CysF 5His } \\
\text { His-tagged N6162S N115Q }\end{array}$ & pcDNA3 N6162S N115Q CysF & $\begin{array}{l}\text { cysF-6H-pCDNA_F } \\
\text { cysF-6H-pCDNA_R }\end{array}$ \\
\hline N65K-His & $\begin{array}{l}\text { pcDNA3 N65K CysF 5His } \\
\text { His-tagged N65K }\end{array}$ & pcDNA3 N65K CysF & $\begin{array}{l}\text { cysF-6H-pCDNA_F } \\
\text { cysF-6H-pCDNA_R }\end{array}$ \\
\hline$\Delta \mathrm{N}$-His & $\begin{array}{l}\text { pcDNA3 dNCysF } 5 \text { His } \\
\text { His-tagged } \Delta N\end{array}$ & pcDNA3 dNCysF & $\begin{array}{l}\text { cysF-6H-pCDNA_F } \\
\text { cysF-6H-pCDNA_R }\end{array}$ \\
\hline$\Delta \mathrm{N}$ N65K-His & $\begin{array}{l}\text { pcDNA3 dN N65Q CysF 5His } \\
\text { His-tagged } \Delta \text { N N65K }\end{array}$ & pcDNA3 dN N65Q CysF & $\begin{array}{l}\text { cysF-6H-pCDNA_F } \\
\text { cysF-6H-pCDNA_R }\end{array}$ \\
\hline
\end{tabular}

\section{Immunoflourescence Staining}

For immunofluorescence staining, HeLa and Hek293 cells were grown on Poly-L-lysine-coated coverslips, transfected using PolyJet DNA Transfection Reagent (SL100688, Sinangen), following the manufacturer's instructions, then grown for another $24 \mathrm{~h}$. Cell media were removed, centrifuged, and used in internalization assays for the non-transfected cells. The cells were washed with PBS, fixed with $4 \%$ paraformaldehyde (15710, Electron Microscopy Sciences) in PBS (10 min), followed by 10 min permeabilization in $0.1 \%$ Triton X-100 in PBS. Non-specific staining was blocked with 3\% BSA in PBS for $1 \mathrm{~h}$. Cells were co-stained with primary, affinity-purified rabbit anti-cystatin F, mouse monoclonal anti LAMP-1 antibody (ab25630, Abcam) and goat polyclonal anti Golgin-97 (sc-74632, Santa Cruz Biotechnology) and secondary antibodies, donkey anti-mouse conjugated with Alexa Fluor 488 (2.5 $\mu \mathrm{g} / \mathrm{mL}, \mathrm{A}-21202$, Thermo Fisher Scientific), donkey anti-rabbit antibodies conjugated with Alexa Fluor 546 $(2.5 \mu \mathrm{g} / \mathrm{mL}, \mathrm{A}-10040$, Thermo Fisher Scientific), donkey anti-goat antibodies conjugated with Alexa Fluor $633(2.5 \mu \mathrm{g} / \mathrm{mL}, \mathrm{A}-31570$, Thermo Fisher Scientific), each time for $1 \mathrm{~h}$ in the presence of 3\% BSA in PBS. Cells were washed three times with PBS after each of these steps. Lysotracker Red DND (L7528, Thermo Fisher
Scientific) was purchased from Life Technologies. For cystatin F staining, affinity-purified rabbit anti-cystatin $\mathrm{F}$ antibody (Davids Biotechnologie, $\mathrm{GmbH}$, Germany) raised against recombinant human cystatin $\mathrm{F}$ was used unless stated otherwise.

For internalization assays, HeLa and Hek293 cells were grown on glass coverslips for $12 \mathrm{~h}$ before the addition of cystatin F-containing conditioned media from transfected cells or of control media, grown for an additional $24 \mathrm{~h}$ and stained as described above. Cells were mounted on glass slides with Prolong Gold Antifade Reagent containing nuclear 4',6-diamidino-2-phenylindole stain (P36935, Thermo Scientific). Cells were imaged using an LSM-710 confocal microscope (Carl Zeiss, Germany) using a 63 PlanFluar/NA 1.45 objective and ZEN 2010 B SP1 software (Carl Zeiss) followed by processing with ZEN 2010 B SP1 software. Images were obtained by sequential excitation with Diode (405-30), Argon (488), HeNe (543), and/or HeNe (633) lasers, using a separate channel for a specific fluorophore in order to avoid cross-talk between different fluorophores.

\section{Immunoblotting and Protease Assays}

Glycosylation status of cell culture medium of HeLa cells transfected with pcDNA3 containing different untagged cystatin $\mathrm{F}$ 
mutants was analyzed with N-glycosidase F (PGNase; Roche). The samples were prepared according to manufacturer's instructions. Briefly, $4 \mu \mathrm{g}$ of cell culture media were mixed with reaction buffer (Roche) and boiled for $10 \mathrm{~min}$ at $100^{\circ} \mathrm{C}$. Once cooled, $3 \mathrm{U}$ of $\mathrm{N}$-glycosidase $\mathrm{F}$ (PGNase) was added and the reaction was incubated overnight at $37^{\circ} \mathrm{C}$. For western blot analysis, the cells were detached using mild dissociating reagent TrypLE Select (12563029, Gibco), washed once with ice-cold PBS, and lysed ( $10^{8}$ cells/mL RIPA buffer: $0.15 \mathrm{M} \mathrm{NaCl}, 1 \%$ TritonX-100, $0.1 \%$ SDS, $50 \mathrm{mM}$ Tris, $\mathrm{pH} 8.0$ ), supplemented with protease and phosphatase inhibitor cocktail tablets (PhosSTOP with cOmplete and cOmplete ULTRA Protease Inhibitor Tablets, Roche, Switzerland). NK-92 and primary NK cells were washed twice in ice-cold PBS and lysed under the same conditions as described above. Protein concentration was determined with DC Protein Assay (5000116, Bio-Rad Laboratories). Immunoblotting proteins were separated by 12 and 15\% SDS-PAGE as described (43). Membranes were blocked for $1 \mathrm{~h}$ in 5\% non-fat dry milk in TBS with $0.5 \%$ Tween-20 (for anti-Granzyme B antibody) or with PBS for other antibodies. Primary antibodies diluted in blocking solution were incubated overnight at $4^{\circ} \mathrm{C}$. Antibodyreactive proteins were detected by incubation, in blocking solution for $1 \mathrm{~h}$, with horseradish peroxidase (HRP)-conjugated secondary antibodies (anti-rabbit-HRP, 111-035-045, Jackson ImmunoResearch or anti-mouse-HRP, 715-035-150, Jackson ImmunoResearch) or in the dark with fluorescent secondary antibodies [goat anti-mouse IgG $(\mathrm{H}+\mathrm{L})$-DyLight 550, 84540 or goat anti-rabbit IgG $(\mathrm{H}+\mathrm{L})$-DyLight 650, 84546, Invitrogen]. Membranes with HRP-conjugated antibodies were visualized with LumiLight Plus Western Blotting substrate (12015196001, Roche). Images were acquired using a GelDoc System (Bio-Rad), processed, and quantified using Image Lab Software (Bio-Rad). We used antibody raised against $63 \mathrm{AA}$ in the C-terminal part of cystatin F (HPA040442, Sigma-Aldrich) for analysis of NK and NK-92 cell lysates, culture media and cell lysates (Hek293 and HeLa cells) upon transfection and internalization. Other antibodies used in western blots include: mouse anti- $\beta$-actin (ab8226, Abcam), mouse monoclonal antibody for Granzyme B (sc-8022, Santa Cruz Biotechnology), and mouse anti-GAPDH antibody (sc-32233, Santa Cruz Biotechnology).

For protease assays the cells were washed in PBS and detached using TrypLE Select (Invitrogen). All subsequent steps were carried out at $4^{\circ} \mathrm{C}$. Cells were centrifuged $(300 \mathrm{~g})$ and washed in PBS. Cell pellets were then resuspended in lysis buffer containing either $50 \mathrm{mM}$ citrate buffer, pH 6.2 with 1\% Triton-X-100 (for cathepsins) or in $25 \mathrm{mM}$ HEPES, pH 7.4 with $250 \mathrm{mM} \mathrm{NaCl}$, $2.5 \mathrm{mM}$ EDTA, $0.1 \% \mathrm{NP}-40$ (for granzymes) and incubated for $15 \mathrm{~min}$. Lysed cells were then centrifuged $(14,000 \mathrm{~g})$ for $20 \mathrm{~min}$ to obtain post-nuclear cell lysates; the pellets were discarded. Protease activity was determined by following the hydrolysis of their respective substrates. The rate of hydrolysis was followed in assay buffer containing $10 \mu \mathrm{g}$ of post-nuclear cell lysates and specific substrates. Each lysate was analyzed in triplicate. The following activation buffers were used: $100 \mathrm{mM}$ MES, $2 \mathrm{mM}$ EDTA, 5 mM dithiothreitol (DTT), pH 6.5 (for cathepsins L and H), $25 \mathrm{mM}$ MES, $100 \mathrm{mM} \mathrm{NaCl}, 5 \mathrm{mM}$ DTT, pH 6 (cathepsin C) and $39 \mathrm{mM}$ citric acid, $121 \mathrm{mM} \mathrm{Na}_{2} \mathrm{HPO}_{4}, 1 \mathrm{mM}$ EDTA, $5 \mathrm{mM}$
DTT pH 5.8 (for legumain), $50 \mathrm{mM}$ Tris, $100 \mathrm{mM} \mathrm{NaCl} \mathrm{pH} 7.4$ (Granzyme B) and $20 \mathrm{mM}$ Tris, $150 \mathrm{mM} \mathrm{NaCl}$, pH 8.1 (Granzyme A). Post-nuclear cell lysates were incubated in black 96-well plates for $15 \mathrm{~min}$ in assay buffer before the addition of substrates: $\mathrm{H}$ Gly-Phe-7-Amido-4-methylcoumarin (AMC) for cathepsin C (70 $\mu \mathrm{M}, \mathrm{I}-1220.0050$, Bachem), H-Arg-AMC for cathepsin $\mathrm{H}$ (20 $\mu$ M, I-1050.0250, Bachem), Z-Phe-Arg-AMC for cathepsin L (50 $\mu \mathrm{M}, \mathrm{I}-1160.0050$ Bachem), benzoyloxycarbonyl-Ala-AlaAsn-AMC (12 $\mu \mathrm{M}, \mathrm{I}-1865.0050$, Bachem) for legumain, acetylIle-Glu-Pro-Asp-AMC for granzyme B (50 $\mu \mathrm{M}$, I-1835.0005, Bachem) and benzoyloxycarbonyl Gly-Pro-Arg-AMC for granzyme A (200 $\mu \mathrm{M}$, I-1150.0025, Bachem). Fluorescence was quantified by measuring (for $30 \mathrm{~min}$ ) excitation at $370 \mathrm{~nm}$ and emission at $460 \mathrm{~nm}$ on microplate reader Infinite M1000 (Tecan). Protease activities are expressed as the rate of AMC release over time.

\section{Isolation of Peripheral Blood NK Cells}

Peripheral blood was obtained from healthy volunteers at the Blood Transfusion Center of Slovenia, according to institutional guidelines. Samples were collected following local ethics committee approval (0120-279/2017-3). Peripheral blood lymphocytes were obtained after Ficoll-hypaque centrifugation and enriched in NK cells by negative selection using the NK Isolation Kit from Miltenyi Biotec (130-092-657) according to the manufacturer's instructions. The purity of NK cell population was found to be greater than $98 \%$, based on flow cytometric analysis of anti-CD3 (300319, BioLegend) and anti-CD56 antibody (130-090-755, Miltenyi Biotech) labeling. NK cells were either used directly, or cultured with or without IL-2 $(1,000 \mathrm{IU} / \mathrm{mL})$ for $48 \mathrm{~h}$ at $37^{\circ} \mathrm{C}$ and $5 \% \mathrm{CO}_{2}$. The levels of contaminating $\mathrm{CD} 3+\mathrm{T}$ cells remained low, at $0.7 \pm 0.01 \%$, similar to those obtained by non-specific staining using isotype control antibody (400147, BioLegend) throughout the experimental procedures. Flow cytometry was performed using the FACSCalibur flow cytometer (Becton Dickinson Immunocytometry System, San Jose, CA, USA) for acquisition and FlowJo software (TreeStar) for sample analysis.

\section{Cytotoxicity Assay}

Cytotoxicity was measured using the Total Cytotoxicity Detection Kit (972, Immunochemistry) based on a flow cytometric analysis, using K562 cells or MCF-7 cells as targets, and NK-92 or primary NK cells as effectors. Target (K562 or MCF-7) cells were fluorescence labeled with carboxyfluorescein succinimidyl ester (CFSE) and added to 96-well flat-bottomed polypropylene microtiter plates (Costar, Corning Life Science). The effector cells were then added to achieve different target: effector cell ratios (1:1, 1:2, 1:5, $1: 10,1: 20$ for NK-92 cells or 1:0.1, 1:0.5, 1:1, 1:2, 1:5 for primary NK cells). Various cystatin F mutants ( $80 \mathrm{nM}$ final concentration) were added to the cell mixture. The samples were incubated for $4 \mathrm{~h}$ at $37^{\circ} \mathrm{C}$ in $5 \% \mathrm{CO}_{2}$, then sulforhodamine-fluorochrome labeled inhibitor of caspases (SR-FLICA) was added to all samples and the cells incubated for another $45 \mathrm{~min}$ at $37^{\circ} \mathrm{C}$. After incubation, the cocultured cell populations of effector and target cells were transferred to round-bottom polystyrene tubes (Falcon, ThermoScientific). Viability stain 7-aminoactinomycin $\mathrm{D}$ (7-AAD) was added following the manufacturer's instructions 
and the samples were acquired within 30 min of staining. All samples were acquired using a FACSCalibur flow cytometer (Becton Dickinson Immunocytometry System, San Jose, CA, USA). Sample acquisition and flow cytometer compensation was done according to the manufacturer's instructions, acquiring 9,000 of target cells per sample. Sample analysis was performed using FlowJo softwear (TreeStar) as previously described (44). Briefly, target cells were gated by their side scatter and FL-1 fluorescence (CFSE-positive staining, FL-1) and 7-AAD uptake (FL-3) and SR-FLICA (FL-2) staining was determined within the gated cells. To determine spontaneous lysis of target cells, samples without effector cells (effector: target concentrations of 0:1 as negative control) were included in the experiments and spontaneous lysis of target cells was subtracted from the cytotoxic percentage obtained for each sample to give the net cytotoxicity percentage. LU 30/10 $0^{6}$ cells were calculated using the inverse of the number of effector cells needed to lyse $30 \%$ of target cells $\times 100$ (38). When testing the effects of anti-cystatin $\mathrm{F}$ antibody on cytotoxicity of NK-92 cells, the cells were activated and mixed with stained target cells as described above, incubated with the antibody (in final concentration $200 \mathrm{mM}$ ) with or without the addition of wild-type cystatin F. After the incubation the cells were further stained and analyzed as described above.

For flow cytometric analysis of exocytosis in the presence of recombinant cystatin F NK-92 cells were activated as described above, incubated with cystatin F mutants ( $80 \mathrm{nM}$ final concentration) for $4 \mathrm{~h}$ and receptor activation independent lytic granule exocytosis was induced by incubation with DAG analog, phorbol myristate acetate (Sigma) (50 nM final concentration), and ionomycin (Sigma) (1 $\mu \mathrm{M}$ final concentration) for $1 \mathrm{hr}$ at $37^{\circ} \mathrm{C}$. Exocytosis was assayed by measuring the binding of anti-CD107a (LAMP-1)-VioBright FITC, human (130-106-233, Miltenyi Biotech) antibody to the externalized lysosome-associated membrane protein 1 (LAMP-1).

\section{Statistical Analysis}

Data were analyzed using GraphPad Prism 5 software. The values represent mean \pm SD of the values obtained. For kinetic data the slopes of linear regression curves were calculated and statistical differences in all experiments were determined using a one-way ANOVA. Statistical significance was accepted when $P<0.05$.

\section{RESULTS}

\section{Subcellular Localization, Secretion, and Uptake of Full-Length Cystatin F and Its Mutants}

The subcellular localization and trafficking of wild-type cystatin $\mathrm{F}$ and its mutants were analyzed in HeLa (Figure 2) and Hek293 (Figure S1 in Supplementary Material) cells that do not express endogenous cystatin F $(14,20)$. Transfection of the cells with wild-type cystatin $\mathrm{F}$ (wt) and a mutant with an altered legumain binding site (N65K) resulted in significant secretion of the protein into the culture medium (Figure 2A; Figure S1A in Supplementary Material). In accordance with previous reports $(16,19)$, both forms were present in the medium exclusively as dimers. Significant amounts of wild-type cystatin F and N65K mutant were retained within the transfected cells, both being only partially converted to the monomeric cystatin F (Figure $\mathbf{2 B}$; Figure S1B in Supplementary Material). As shown by immunofluorescence microscopy, the intracellular fraction of wt cystatin F and N65K mutant was colocalized with "dot like" structures of endo-lysosomal components (LAMP-1 and Lysotracker Red DND labeling) and with components of the Golgi apparatus (Golgin-97 labeling) (Figure 2D; Figure S1D in Supplementary Material). Wild-type cystatin F and its N65K mutant, when added to the culture medium, were also taken effectively up by the cells and converted intracellularly to their monomeric forms (Figure 2C; Figure S1C in Supplementary Material).

Double (N6162S) unglycosylated and (N6162SN115Q) nonglycosylated mutants were also secreted and found as dimers in the cell culture medium. Both mutants were partially retained within the transfected cells (Figure 2B; Figure S1 in Supplementary Material) and were colocalized predominantly with the marker of the biosynthetic/secretory pathway (Golgin-97) (Figure 2D; Figure S1 in Supplementary Material). However, a small amount of their intracellular fraction can be seen as a monomeric form, suggesting M6P-independent trafficking of cystatin $\mathrm{F}$ to the endocytic pathway. Similarly, both double and fully unglycosylated mutants were detected in the recipient cells, although to a much lesser extent than cystatin F, revealing an additional, M6Pindependent mechanism for cystatin F uptake (Figure 2C; Figure S1 in Supplementary Material). However, only a small fraction of the double unglycosylated mutant was present as monomer, and the monomeric form of the non-glycosylated mutant was absent in cell lysates.

\section{Subcellular Localization, Secretion, and Uptake of N-Terminally Truncated Cystatin F Mutants}

N-terminally truncated cystatin $\mathrm{F}(\Delta \mathrm{N})$ and N-terminally truncated cystatin F N65K mutant $(\Delta \mathrm{N} N 65 \mathrm{~K})$ were secreted from transfected cells and were present in the medium solely in the monomeric form (Figure 3A). Surprisingly, a significant amount of these mutants was retained in transfected cells in both monomeric and dimeric forms (Figure 3B). Addition of DTT to cell lysates at concentrations higher than $25 \mathrm{mM}$, prior to SDS-PAGE analysis, reduced the dimeric form to monomers (Figure 3E). Since these mutants lack Cys26, due to the N-terminal truncation, the remaining Cys63 apparently mediates $\Delta \mathrm{N}$ cystatin $\mathrm{F}$ dimerization. Indeed, mutagenesis of Cys63 to Ser completely abolished dimerization of $\mathrm{N}$-terminally truncated cystatin F (Figure 3B; Figure S2B in Supplementary Material). In transfected cells, both (wt and N65K) N-terminally truncated mutants were colocalized with biosynthetic/secretory (Golgin-97) and endo-lysosomes (LAMP-1 or Lysotracker Red DND) markers (Figure 3D; Figure S2D in Supplementary Material). N-terminally truncated cystatin $\mathrm{F}$ (wt and $\mathrm{N} 65 \mathrm{~K}$ ) were also taken up by recipient cells in which only monomeric forms were detected. The non-dimerizing $\Delta$ NC63S mutant was secreted from transfected cells but was not detected inside recipient cells, possibly due to the lower rate of its internalization (Figure 3C; Figure S2C in Supplementary Material). 


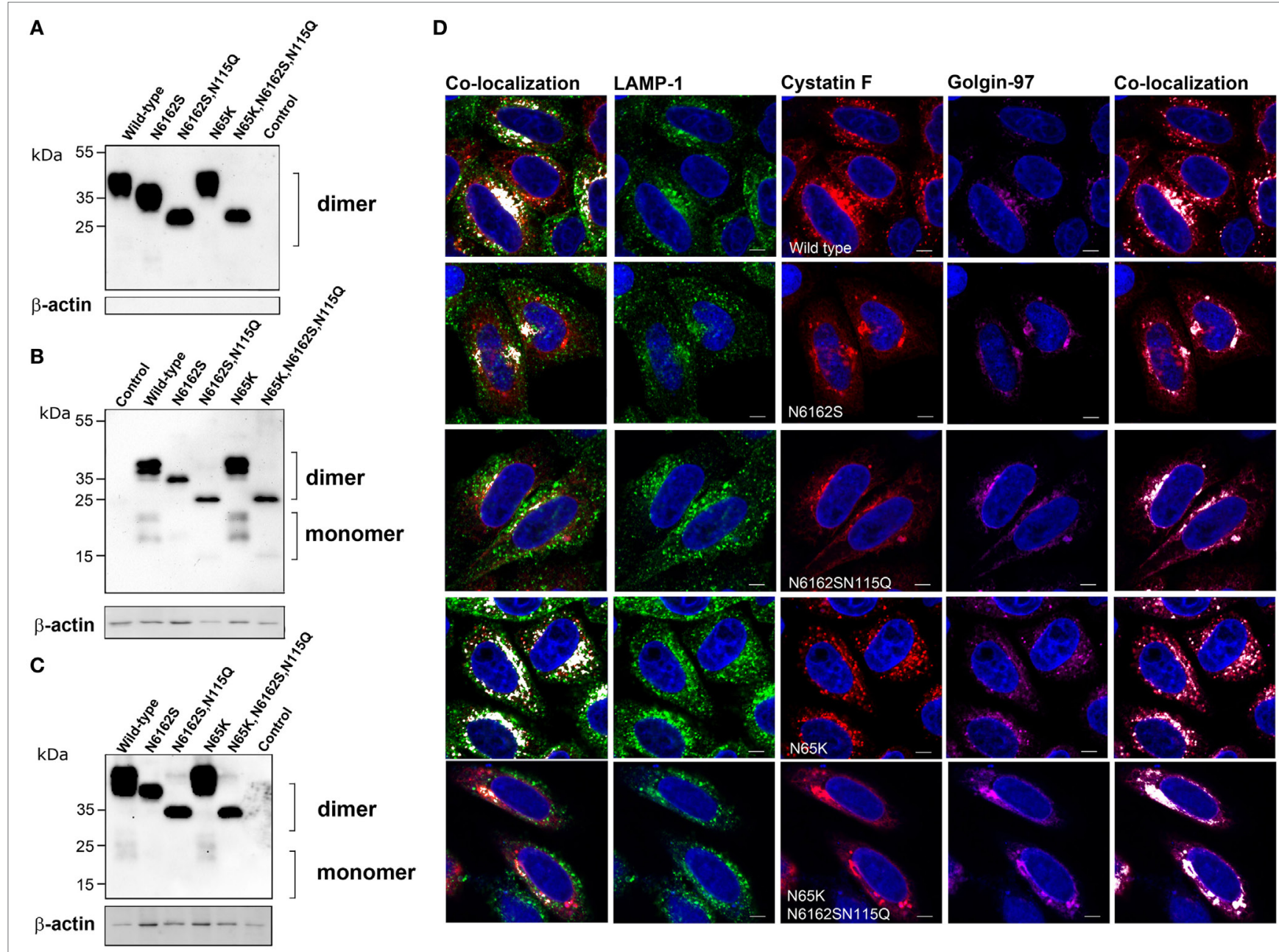

FIGURE 2 | Subcellular localization, secretion and uptake of full-length cystatin F mutants. The different full-length cystatin F mutants were transfected into HeLa cells using PcDNA3 vector. HeLa cells transfected with empty pcDNA3 vector served as controls. To follow the uptake, cell culture medium containing different mutant forms of full-length cystatin F was added to non-transfected HeLa cells. Cell culture medium (A) and cell lysates of transfected (B) and recipient (C) cells were analyzed $24 \mathrm{~h}$ after transfection (A,B) or conditioning (C) by western blot, using non-reducing conditions. $\beta$-actin staining was used to show equivalent protein loading. (D) Cells were studied by immunofluorescence microscopy, following transfection of HeLa cells with different mutant forms of cystatin F. Cells were co-stained with lysosomal (LAMP-1) marker (red) anti-cystatin F antibody (green) and anti-human Golgin-97 (purple) antibody, followed by secondary antibodies conjugated with Alexa Fluor 488 (LAMP-1), Alexa Fluor 555 (cystatin F) and Alexa Fluor 633 (Golgin-97). Images were taken at 63× magnification.

\section{The Effects of Cystatin F Mutants on the Activity of Cathepsins H, L, C, and}

\section{Legumain}

The effects of cystatin F mutants were examined on the activity of the intracellular peptidases cathepsins $\mathrm{C}, \mathrm{H}, \mathrm{L}$ and legumain in whole cell lysates prepared from cells that were either transfected (Figure 4) or exposed to cell culture medium containing cystatin $\mathrm{F}$ mutants for $24 \mathrm{~h}$ (Figure 4). The inhibition results from their trafficking to endosomal/lysosomal vesicles and monomerisation of cystatin $\mathrm{F}$ dimer. Wild-type cystatin $\mathrm{F}$ and N65K mutant reduced the activity of cathepsins $\mathrm{L}, \mathrm{H}$, and $\mathrm{C}$ in all cell lysates tested; however, the effect was weaker for cathepsin $\mathrm{H}$ than for the other two cathepsins. As expected, wt cystatin F inhibited legumain, while N65K mutants did not. Accordingly, N-terminally truncated cystatin $\mathrm{F}$ and $\Delta \mathrm{NN} 65 \mathrm{~K}$ mutant both inhibited cathepsins $\mathrm{L}, \mathrm{C}$, and $\mathrm{H}$, since they were already present in monomeric forms and did not need prior activation.

For the double unglycosylated mutant N6162S, the inhibition of cysteine cathepsins and legumain was much weaker than that of the fully glycosylated forms and wt cystatin $\mathrm{F}$, in line with limited trafficking to the endosomal/lysosomal vesicles, Further, in accord with the absence of the monomeric form and the lack of localization to endo/lysosomal vesicles, the non-glycosylated cystatin F mutant (N6162SN115Q) did not inhibit any of the peptidases tested.

\section{The Effects of Cystatin F Mutants on the Cytotoxicity of NK-92 Cells and Primary NK Cells}

In order to gain a better insight into the mechanisms involving cystatin $\mathrm{F}$ in its cytotoxic function, we determined its levels 


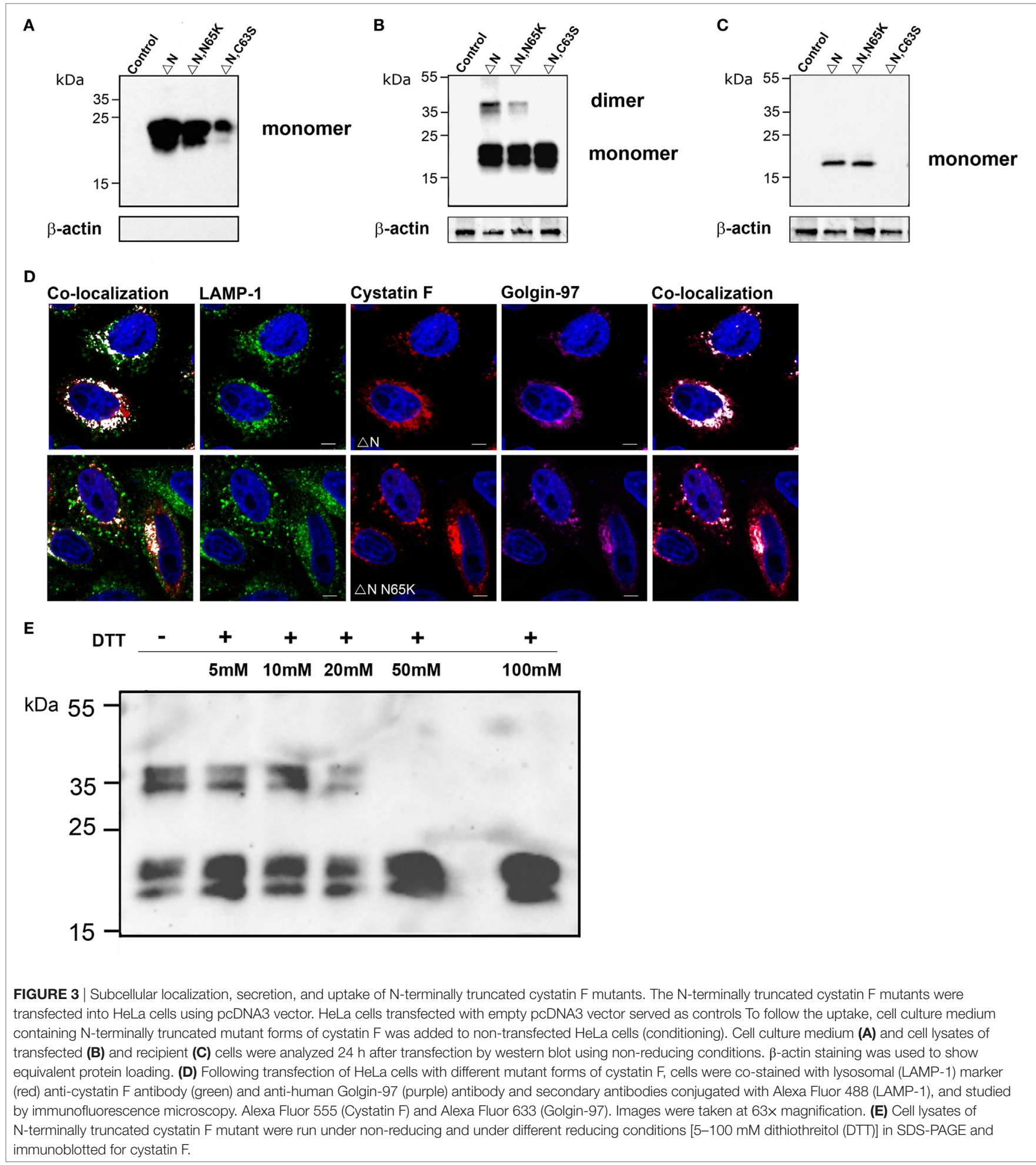

together with the activities of legumain, granzymes $\mathrm{A}$ and $\mathrm{B}$ and pro-granzyme convertases cathepsins $\mathrm{C}$ and $\mathrm{H}$ upon the stimulation of NK-92 and primary NK cells with IL-2, which is known to increase the expression of multiple effector molecules essential for NK cytotoxic function $(45,46)$. We showed that, on stimulation with IL-2, the expression of the dimeric form of cystatin F remained unchanged in NK-92 cells whereas, in primary NK cells, it was significantly increased (Figure $\mathbf{5 A}$ ), similarly to that observed by Magister et al. (38). Again, the level of monomeric cystatin $\mathrm{F}$ remained unchanged in primary NK cells on IL-2 stimulation. Furthermore, the activity of cathepsin C increased in primary NK cells but not in NK-92 


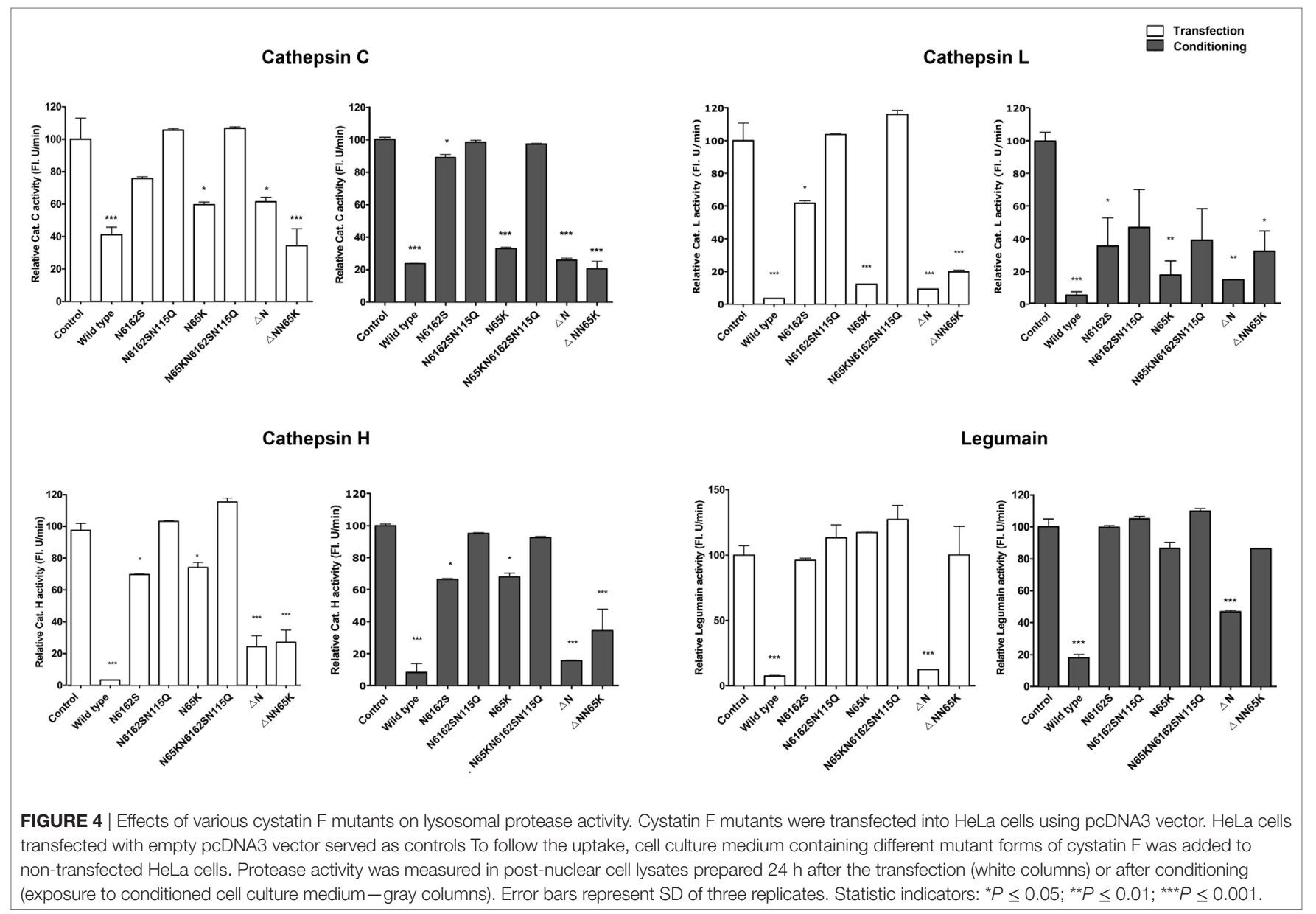

cells (Figure S5 in Supplementary Material). Similarly, unlike in NK-92 IL-2 significantly increased the protein level of granzyme $\mathrm{B}$ and activity levels of granzymes B and A in primary NK cells (Figure 5B; Figure S5C in Supplementary Material). To demonstrate that active monomeric cystatin $\mathrm{F}$ regulates the activation of granzymes A and B, we exposed NK-92 cell lysates to the same concentration $(80 \mathrm{nM})$ of different cystatin F mutants. A significant decrease was observed in the activity of granzymes at both incubation times tested (Figure 5C), the effect being more pronounced after $4 \mathrm{~h}$ incubation. As expected, the $\Delta \mathrm{N}$ mutant, present predominantly as an active monomer, caused the most significant decrease in the granzymes' activities.

Further, the effects of cystatin F mutants were determined on the granule-mediated cytotoxicity of NK-92 (Figure 6A) and of primary NK cells (Figures 6B,C) on stimulation with IL-2. To ensure that the NK cells used in our experiments kill target cells predominantly via the $\mathrm{Ca}^{2+}$-dependant granule release pathway, and not through Fas-mediated cell death, K562 erythroleukemia cells were chosen as target cells (47). Further, we demonstrated that primary NK cells are also capable of lysing MCF-7 cells, which have low levels of Fas receptor (FasR) and are resistant to anti-FasR antibody mediated apoptosis (48) (Figure S4 in Supplementary Material). As perforin activity is calcium dependent (49), the killing assay was performed in the presence of the calcium chelator EGTA, and $\mathrm{MgCl}_{2}$ was used to confirm that primary NK cells kill targets in the granule dependant pathway (Figure S4 in Supplementary Material). We showed that the incubation with wild-type cystatin $\mathrm{F}$ and its $\mathrm{N}$-terminally truncated mutant $\mathrm{F}$ did not affect the lytic granule exocytosis in activated NK-92 cells (Figure S6 in Supplementary Material).

Wild-type cystatin $\mathrm{F}$ and its N65K mutant significantly decreased the cytotoxicity of NK-92 and primary NK cells (Figure 6; Figure S6 in Supplementary Material) at all target to effector ratios measured $(P \leq 0.05 ; P \leq 0.01$ ) whereas the wild-type cystatin $\mathrm{F}$, incubated with the $2.5 \mathrm{M}$ excess of the anti-cystatin F antibody did not affect the cytotoxicity of NK-92 cells (Figure S6 in Supplementary Material). Antibody alone also did not affect cell cytotoxicity. N-terminally truncated mutants of cystatin $\mathrm{F}$ had the most pronounced impact on cell cytotoxicity, reducing target cell killing by $\geq 20 \%$ in both NK-92 cells $(P \leq 0.01)$ and primary NK cells $(P \leq 0.01 ; P \leq 0.001)$. Finally, the non-glycosylated mutant N6162SN115Q had no significant effect on cytotoxic killing of targets in either NK cell type tested.

\section{DISCUSSION}

Cystatin $\mathrm{F}$ has recently been identified as an upstream regulator of split anergy in NK cells (38). Since this inhibitor can be produced and secreted by tumor cells $(34,35)$, we investigated whether extracellular cystatin F can reduce the cytotoxicity of 

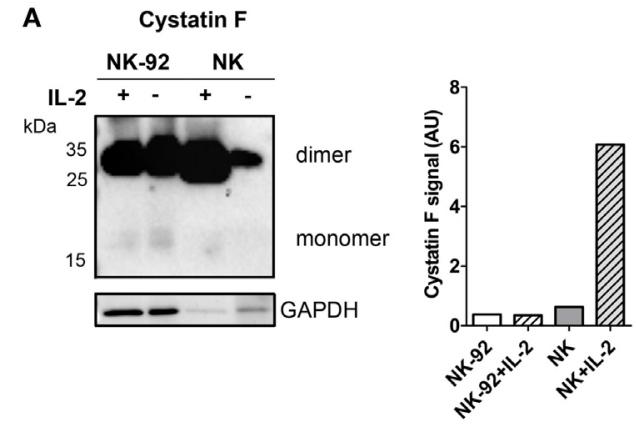

B

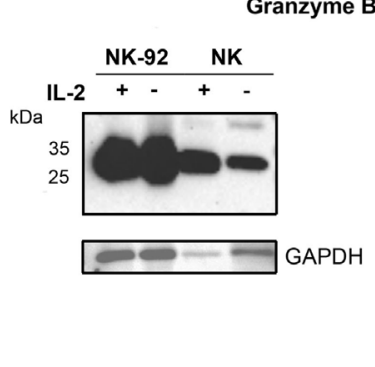

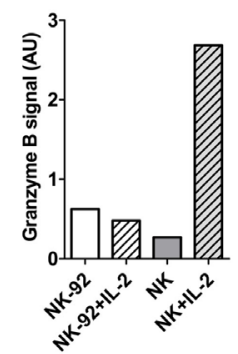

C
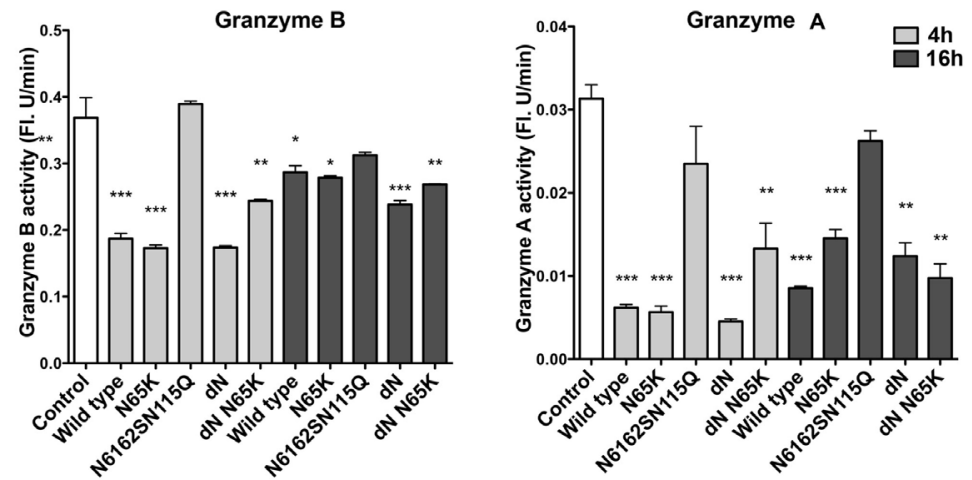

FIGURE 5 | Expression and activity of the main components of cytotoxic machinery of NK-92 and isolated primary NK cells. Non-stimulated and IL-2-stimulated NK-92 and isolated primary NK cells were lysed and analyzed by non-reducing PAGE for protein levels of cystatin $F(\mathbf{A})$ and granzyme B (B) by immunoblotting. Proteolytic activity of granzyme B and granzyme A was measured in post-nuclear cell lysates prepared from IL-2-stimulated NK-92 after 4 and $16 \mathrm{~h}$ incubation with different cystatin $\mathrm{F}$ mutants. Error bars represent SD of three replicates. Statistic indicators: ${ }^{\star} P \leq 0.05 ;{ }^{* *} P \leq 0.01 ;{ }^{* \star *} P \leq 0.001$. (C). GAPDH staining was used to show protein loading and signal intensities for cystatin $\mathrm{F}$ and granzyme $\mathrm{B}$ were normalized to the signal from loading control $(\mathbf{A}, \mathbf{B})$.
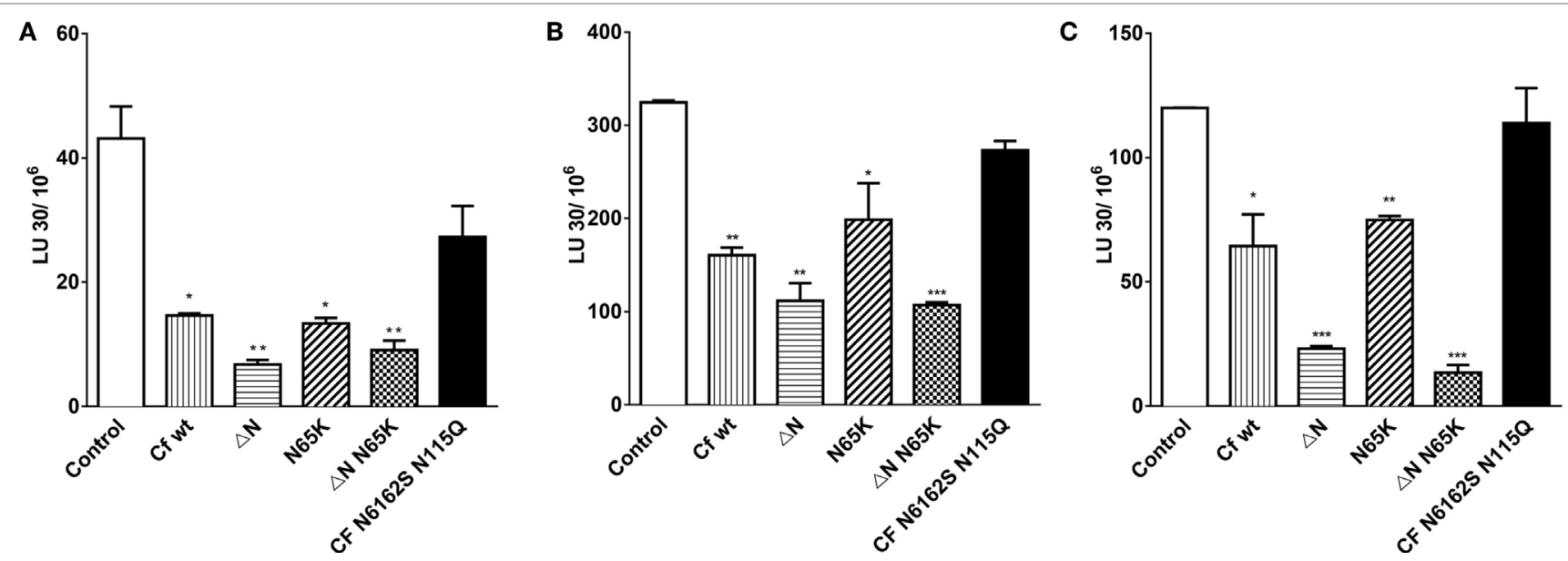

FIGURE 6 | The effects of different mutant forms of cystatin F on the cytotoxicity of NK-92 and primary NK cells toward K562 target cells. Cytolytic activity of IL-2 activated NK-92 cells against K562 erythroleukemia cells at different target to effector ratios (A). Cytolytic activities of primary NK cells isolated from two representative (healthy) individuals were cultured for $48 \mathrm{~h}$ with IL-2, and tested against K562 erythroleukemia cells at different target to effector ratios (B,C). Various cystatin F mutants $(80 \mathrm{nM})$ were added to effector and target mixtures and incubated for $4 \mathrm{~h}$. \% Cytotoxicity was determined at different E:T ratio, and LU 30/10 $\mathrm{cells}$ were calculated using the inverse of the number of effectors needed to lyse $30 \%$ of the tumor cells $\times 100$. Statistic indicators: ${ }^{*} P \leq 0.05,{ }^{\star *} P \leq 0.01$, and ${ }^{\star \star \star} P \leq 0.001$.

NK cells. We found that cystatin F, in both inactive dimeric and activated $\mathrm{N}$-terminally truncated forms, can be taken up effectively by cells and targeted to lysosomes. Within the lysosomes, cystatin $\mathrm{F}$ inactivates cathepsins $\mathrm{C}$ and $\mathrm{H}$, major convertases capable of generating active granzymes and the main executors of cell cytotoxicity. This, in turn, leads to diminished cytotoxicity. 
$\mathrm{N}$-glycosylation of cystatin $\mathrm{F}$ has a significant impact on internalization. For mutants lacking two or three $\mathrm{N}$-glycosylated sites, internalization gradually decreased. On the other hand, the binding site for $\mathrm{C} 13$ protease, legumain, was found to have no effect on cystatin $\mathrm{F}$ internalization or endosomal/lysosomal targeting. These results, therefore, offer an insight into the physiological consequences of the acquisition of cystatin $\mathrm{F}$ by bystander cells and its possible role as a mediator of immune suppression.

It has been shown that the regulatory function of cystatin $\mathrm{F}$ depends on two events-trafficking to the endosomal/lysosomal pathway and proteolytic cleavage of an N-terminal peptide (18, 20). The intracellular trafficking is critically dependent on the number of $\mathrm{N}$-linked carbohydrates $(16,18)$. This is emphasized by the finding that, apart from canonical glycosylation sequences including Asn62 and Asn115, cystatin F possesses an alternative non canonical glycosylation site at Asn61 that can be glycosylated in the case of altered Asn62 (16). It was proposed that $\mathrm{N}$-linked glycans on either Asn61 or Asn62 are required for M6Pdependent intracellular trafficking to endosomes/lysosomes and for cell uptake, whereas glycosylation at Asn115 is not important. To test this hypothesis on our cell model, we prepared a double unglycosylated mutant N6162S and a non-glycosylated mutant N6162SN115Q. Compared to wild-type cystatin F or to mutants without an altered glycosylation pattern, their presence is indeed lower within the endosomal/lysosomal pathway; however, it is not completely absent. In particular, the double N6162S mutant is able to co-localize with the lysosomal marker LAMP-1 and partially inhibits the proteolytic activity of various lysosomal peptidases, suggesting that glycosylation of Asn115 also contributes to M6P targeting and/or that endosomal/lysosomal trafficking of cystatin $\mathrm{F}$ could be, in part, glycosylation independent.

The question arose as to whether the $\mathrm{N}$-terminally truncated monomeric form of cystatin $\mathrm{F}$ can also be targeted to the endo/ lysosomal pathway, can be secreted, or can be internalized by recipient cells. In HeLa and Hek293 cells, we demonstrated that the truncated ( $\Delta \mathrm{N}$ mutant) cystatin $\mathrm{F}$ was effectively targeted to the endo/lysosomes, inhibiting the examined cathepsins. Like wild-type dimeric cystatin F, the truncated form was secreted to the medium and, moreover, was internalized by both HeLa and Hek293 cells. The latter observation appears to contradict those of Colbert et al. (16) that indicate that only the dimeric form of cystatin F can be taken up by mouse L929 cells. This apparent discrepancy can be explained by the difference in cell types/species used, i.e., Hek293T as producers and mouse L929 as receivers of cystatin F, given that mouse cystatin $\mathrm{F}$ has only one $\mathrm{N}$-linked carbohydrate chain at a site homologous to Asn62 whereas, in human cystatin F, Asn62 and Asn115 can carry carbohydrate chains. The other explanation is that, despite the absence of Cys26, truncated cystatin $\mathrm{F}$ can be present in lysates of transfected cells as both a monomer and a dimer. The dimer dissociated only on exposure to reducing conditions (25 mM DTT) that are quite strong, although lower than those needed for dissociation of regular full-length cystatin F dimer [100 mM DTT (19)]. Similarly, Hamilton et al., showed dimer formation on substitution of Cys 26 in full-length cystatin F (20). We investigated whether this dimeric form constitutes an intermediate that can enable translocation of cystatin F from biosynthetic cellular compartments or cell culture medium to endo/ lysosomes. Dimerization was prevented by replacing Cys63 with Ser, confirming that the disulfide bond between Cys63 residues is responsible for dimerization of $\mathrm{N}$-terminally truncated cystatin $\mathrm{F}$. Therefore, besides the regular cystatin $\mathrm{F}$ dimer, formed through two disulfide bonds between Cys26 on one subunit and Cys63 on the other, we can find, in extracellular space, a dimer of truncated, activated cystatin F, formed by a disulfide bond between two Cys63 residues. Active monomeric cystatin $\mathrm{F}$, derived from $\Delta \mathrm{N}$ cystatin $\mathrm{F}$ dimer, could inhibit the extracellularly located cysteine peptidases. This is important for cancer cells, particularly those at the invasive edges of tumors, as they often shift the lysosomes from a perinuclear area to the cell periphery, secreting the lysosomal contents into the extracellular space (50). Furthermore, these results extend the concept of "in trans" regulation of the peptidases to activated truncated cystatin $\mathrm{F}$ which, upon internalization to recipient cells, does not require the presence of an activating peptidase, such as the putative activator cathepsin V (51), for monomerization and subsequent regulation of lysosomal peptidases.

The second binding site of cystatin F, inhibiting the $\mathrm{C} 13$ peptidase family, could also affect cell trafficking and internalization. To test this possibility, we prepared a full-length and an $\mathrm{N}$-terminally truncated N65K mutant, which is not able to bind legumain, a member of $\mathrm{C} 13$ peptidases. In HeLa and Hek293 cells, which do not normally express cystatin F $(14,20)$, a transfected N65K mutant was targeted to endo/lysosomes to the same extent as the wild-type cystatin F. Both forms were taken up by the cells and converted to their active forms, indicating that the binding site for C13 proteases is not involved in the trafficking, internalization, or activation of cystatin F. The ability to inhibit cathepsins $\mathrm{C}$ and $\mathrm{L}$ did not differ significantly between these two forms; however, the effect of the $\mathrm{N} 65 \mathrm{~K}$ mutant on the activity of cathepsin $\mathrm{H}$ was less pronounced, probably because legumain is a peptidase involved in the activation of cathepsin $\mathrm{H}$ (52).

Its unique expression pattern and inhibitory properties make cystatin $\mathrm{F}$ a good candidate for the regulation of granule-mediated cell cytotoxicity. It has been shown that, in NK cells, cystatin F is present, not only in the dimeric form but in an N-terminally truncated monomeric form that potently inhibits granzyme convertase cathepsin C $(20,38)$. Furthermore, in human cytotoxic CD8+ T cells, which share the same granule-mediated cytotoxic mechanism as NK cells, the interaction of cystatin F with cathepsin C was confirmed by immmunoprecipitation (20).

The impact of cystatin F on the cytotoxicity of NK cells was studied using the NK-92 cell line and primary NK cells isolated from peripheral blood, both stimulated with IL-2. The stimulation of NK cells with IL-2 results in activation of a set of genes coding for effector molecules (perforin, granzyme B, Fas ligand, and TRAIL) which increase NK cell lytic potential. However, as in the previous study (38), the IL-2 stimulation increased the cytotoxicity of primary NK cells more significantly than that of NK-92 cells (Figure 5). In line with this was the increased activity of cathepsin $\mathrm{C}$ and protein and the activity levels of granzyme $B$ in primary NK cells, but not in NK-92 cells. Cystatin F was also significantly increased in primary NK cells after stimulation with IL-2, but only as a dimer-the level of the monomeric form remained unchanged. The increase in transcription and de novo synthesis of granzymes $(45,46)$, together with the zymogen 
activation of cathepsin $\mathrm{C}$ and the unchanged level of monomeric active cystatin $\mathrm{F}$, therefore correlates with the increased cytotoxicity of primary NK cells upon stimulation with IL-2. It is not clear why the increased dimeric cystatin $\mathrm{F}$ is not processed into active monomers. Maybe, dimers do not reach the endosomal/ lysosomal vesicles or IL-2 does not stimulate the expression of activating protease. However, the addition of cystatin $\mathrm{F}$ wt and its mutants to IL-2-stimulated primary NK cells and to NK-92 cells led to a significant decrease in their cytotoxicity toward K562 targets. As expected, the effect was more pronounced with active monomeric mutants, which effectively reduced cell cytotoxicity in both cell types. However, the decrease in cytotoxicity was significant, with wt cystatin $\mathrm{F}$ and full-length mutants forming inactive dimer, meaning that NK cells possess a peptidase that activates dimeric cystatin $\mathrm{F}$ within the endosomal/lysosomal vesicles. It has been reported that unstimulated NK-92 cells express cathepsin V (51) whereas there is no information on the expression of cathepsin $\mathrm{V}$ in activated NK-92 cells and in primary NK cells. Besides pro-granzyme convertases cathepsins $\mathrm{C}$ and $\mathrm{H}$, active monomeric cystatin $\mathrm{F}$ can inhibit cathepsin $\mathrm{L}$, a peptidase involved in processing perforin from its precursor form. Its lower level can, in addition, reduce NK cell cytotoxicity. The addition of fully unglycosylated cystatin F (non-glycosylated mutant N6162SN115Q) had no significant effects on the cytotoxicity of NK-92 and primary NK cells, confirming that, as in HeLa and Hek293 cells, non-glycosylated cystatin F is not internalized and targeted to lysosomes. Cystatin F, with a mutated binding site for legumain, showed the same effect on NK cell cytotoxicity as the wild-type cystatin F. This could be explained partially by the very low activity of legumain in NK-92 cells (51). IL-2 reduced legumain activity in primary NK cells although its level remained higher than in NK-92 cells (Figure S5 in Supplementary Material). Nevertheless, the role of legumain in the activation of effector molecules of cytotoxic cells remains controversial. It has been reported that legumain-null mice display lower NK cell activity (11). This could be a result of diminished perforin processing, since legumain has been shown to process cathepsin L (10). Alternatively, legumain inhibition should result in decreased activation of cathepsin $\mathrm{H}$, and consequently pro-granzyme activation; however, our results do not support these observations.

\section{CONCLUSION}

Our results demonstrate that cystatin $\mathrm{F}$ secreted from target cells can be internalized to NK cells and affect their cytotoxic

\section{REFERENCES}

1. Imai K, Matsuyama S, Miyake S, Suga K, Nakachi K. Natural cytotoxic activity of peripheral-blood lymphocytes and cancer incidence: an 11-year follow-up study of a general population. Lancet (2000) 25(356):1795-9. doi:10.1016/ S0140-6736(00)03231-1

2. Sabry M, Lowdell MW. Tumor-primed NK cells: waiting for the green light. Front Immunol (2013) 4:408. doi:10.3389/fimmu.2013.00408

3. Cho D, Shook DR, Shimasaki N, Chang YH, Fujisaki H, Campana D. Cytotoxicity of activated natural killer cells against pediatric solid tumors. Clin Cancer Res (2010) 1(16):3901-9. doi:10.1158/1078-0432.CCR-10-0735 effectiveness. The effect is most pronounced for dimeric inactive cystatin F; however, its N-terminally truncated, active monomeric form can also be internalized and enter the endo/ lysosomal compartments. We have shown that the glycosylation pattern determines the internalization rate of both dimeric and monomeric cystatin F. Within the endosomal/lysosomal vesicles and secretory granules, active cystatin $\mathrm{F}$ decreases the activity of cathepsins $\mathrm{C}$ and $\mathrm{H}$, pro-granzyme convertases and cathepsin $\mathrm{L}$, involved in the processing of perforin, in this way regulating NK cell cytotoxicity. Increased expression and secretion of cystatin F in human cancer cell lines (34) and metastatic cells (35) have been presented, however clear in vivo evidence showing that cystatin $\mathrm{F}$ secreted from tumor cells or cells present in the tumor microenvironment can indeed affect the activity of NK cells has yet to be demonstrated. Prevention of cell internalization or monomerization of cystatin $\mathrm{F}$ by modifying the glycosylation profile or by targeting the peptidase responsible for cystatin $\mathrm{F}$ activation could greatly increase the cytotoxic potential of NK cells and improve the existing immunotherapies for cancer patients.

\section{AUTHOR CONTRIBUTIONS}

MPN, JS, and JK conceived and designed the experiments. MPN performed the experiments. JS contributed to the implementation of the research. UŠ provided help and material for some experiments. AJ provided ideas to design the study. MPN and JK wrote the manuscript. All authors reviewed the manuscript.

\section{ACKNOWLEDGMENTS}

The authors are grateful to Professor Roger H. Pain for critical reading of the manuscript.

\section{FUNDING}

This work was supported by the Research Agency of the Republic of Slovenia Grant J4-6811 to JK.

\section{SUPPLEMENTARY MATERIAL}

The Supplementary Material for this article can be found online at http://www.frontiersin.org/article/10.3389/fimmu.2017.01459/ full\#supplementary-material.

4. Hayakawa Y, Kelly JM, Westwood JA, Darcy PK, Diefenbach A, Raulet D, et al. Cutting edge: tumor rejection mediated by NKG2D receptor-ligand interaction is dependent upon perforin. J Immunol (2002) 15(169):5377-81. doi:10.4049/jimmunol.169.10.5377

5. Trapani JA, Smyth MJ. Functional significance of the perforin/granzyme cell death pathway. Nat Rev Immunol (2002) 2:735-47. doi:10.1038/nri911

6. Bird PI, Trapani JA, Villadangos JA. Endolysosomal proteases and their inhibitors in immunity. Nat Rev Immunol (2009) 9:871-82. doi:10.1038/nri2671

7. Sutton VR, Trapani JA. Proteases in lymphocyte killer function: redundancy, polymorphism and questions remaining. Biol Chem (2010) 391:873-9. doi:10.1515/BC.2010.088 
8. Perisic Nanut M, Sabotic J, Jewett A, Kos J. Cysteine cathepsins as regulators of the cytotoxicity of NK and T cells. Front Immunol (2014) 5:616. doi:10.3389/ fimmu.2014.00616

9. Sutton VR, Waterhouse NJ, Browne KA, Sedelies K, Ciccone A, Anthony D, et al. Residual active granzyme B in cathepsin C-null lymphocytes is sufficient for perforin-dependent target cell apoptosis. J Cell Biol (2007) 12(176):425-33. doi:10.1083/jcb.200609077

10. Konjar S, Sutton VR, Hoves S, Repnik U, Yagita H, Reinheckel T, et al. Human and mouse perforin are processed in part through cleavage by the lysosomal cysteine proteinase cathepsin L. Immunology (2010) 131:257-67. doi:10.1111/j.1365-2567.2010.03299.x

11. Chan CB, Abe M, Hashimoto N, Hao C, Williams IR, Liu X, et al. Mice lacking asparaginyl endopeptidase develop disorders resembling hemophagocytic syndrome. Proc Natl Acad Sci U S A (2009) 13(106):468-73. doi:10.1073/ pnas.0809824105

12. Rawlings ND, Barrett AJ. Evolution of proteins of the cystatin superfamily. J Mol Evol (1990) 30:60-71. doi:10.1007/BF02102453

13. Turk B, Turk D, Salvesen GS. Regulating cysteine protease activity: essential role of protease inhibitors as guardians and regulators. Curr Pharm Des (2002) 8:1623-37. doi:10.2174/1381612023394124

14. Cappello F, Gatti E, Camossetto V, David A, Lelouard H, Pierre P. Cystatin F is secreted, but artificial modification of its C-terminus can induce its endocytic targeting. Exp Cell Res (2004) 15(297):607-18. doi:10.1016/j.yexcr.2004. 03.048

15. Schuttelkopf AW, Hamilton G, Watts C, van Aalten DM. Structural basis of reduction-dependent activation of human cystatin F. J Biol Chem (2006) 16(281):16570-5. doi:10.1074/jbc.M601033200

16. Colbert JD, Plechanovova A, Watts C. Glycosylation directs targeting and activation of cystatin $\mathrm{f}$ from intracellular and extracellular sources. Traffic (2009) 10:425-37. doi:10.1111/j.1600-0854.2009.00881.x

17. Nathanson CM, Wasselius J, Wallin H, Abrahamson M. Regulated expression and intracellular localization of cystatin F in human U937 cells. Eur J Biochem (2002) 269:5502-11. doi:10.1046/j.1432-1033.2002.03252.x

18. Colbert JD, Matthews SP, Kos J, Watts C. Internalization of exogenous cystatin F supresses cysteine proteases and induces the accumulation of single-chain cathepsin L by multiple mechanisms. J Biol Chem (2011) 09(286):42082-90. doi:10.1074/jbc.M111.253914

19. Langerholc T, Zavasnik-Bergant V, Turk B, Turk V, Abrahamson M, Kos J. Inhibitory properties of cystatin $\mathrm{F}$ and its localization in $\mathrm{U} 937$ promonocyte cells. FEBS J (2005) 272:1535-45. doi:10.1111/j.1742-4658.2005. 04594.x

20. Hamilton G, Colbert JD, Schuettelkopf AW, Watts C. Cystatin F is a cathepsin C-directed protease inhibitor regulated by proteolysis. EMBO J (2008) 6(27):499-508. doi:10.1038/sj.emboj.7601979

21. Magister S, Obermajer N, Mirkovic B, Svajger U, Renko M, Softic A, et al. Regulation of cathepsins S and L by cystatin F during maturation of dendritic cells. Eur J Cell Biol (2012) 91:391-401. doi:10.1016/j.ejcb.2012.01.001

22. Alvarez-Fernandez M, Barrett AJ, Gerhartz B, Dando PM, Ni J, Abrahamson M. Inhibition of mammalian legumain by some cystatins is due to a novel second reactive site. J Biol Chem (1999) 2(274):19195-203. doi:10.1074/ jbc.274.27.19195

23. Halfon S, Ford J, Foster J, Dowling L, Lucian L, Sterling M, et al. Leukocystatin, a new class II cystatin expressed selectively by hematopoietic cells. J Biol Chem (1998) 26(273):16400-8. doi:10.1074/jbc.273.26.16400

24. Hashimoto SI, Suzuki T, Nagai S, Yamashita T, Toyoda N, Matsushima K. Identification of genes specifically expressed in human activated and mature dendritic cells through serial analysis of gene expression. Blood (2000) 96(6):2206-14.

25. Magister S, Kos J. Cystatins in immune system. J Cancer (2013) 4:45-56. doi:10.7150/jca.5044

26. Matthews SP, McMillan SJ, Colbert JD, Lawrence RA, Watts C. Cystatin F ensures eosinophil survival by regulating granule biogenesis. Immunity (2016) 19(44):795-806. doi:10.1016/j.immuni.2016.03.003

27. Ni J, Fernandez MA, Danielsson L, Chillakuru RA, Zhang J, Grubb A, et al. Cystatin $\mathrm{F}$ is a glycosylated human low molecular weight cysteine proteinase inhibitor. J Biol Chem (1998) 18(273):24797-804. doi:10.1074/ jbc. 273.38 .24797

28. Obata-Onai A, Hashimoto S, Onai N, Kurachi M, Nagai S, Shizuno K, et al. Comprehensive gene expression analysis of human NK cells and CD8(+)
T lymphocytes. Int Immunol (2002) 14:1085-98. doi:10.1093/intimm/ dxf086

29. Liang J, Li N, Zhang Y, Hou C, Yang X, Shimizu T, et al. Disinhibition of cathepsin $\mathrm{C}$ caused by cystatin $\mathrm{F}$ deficiency aggravates the demyelination in a cuprizone model. Front Mol Neurosci (2016) 9:152. doi:10.3389/fnmol. 2016.00152

30. Ma J, Tanaka KF, Shimizu T, Bernard CC, Kakita A, Takahashi H, et al. Microglial cystatin F expression is a sensitive indicator for ongoing demyelination with concurrent remyelination. J Neurosci Res (2011) 89:639-49. doi:10.1002/jnr.22567

31. Pellagatti A, Vetrie D, Langford CF, Gama S, Eagleton H, Wainscoat JS, et al. Gene expression profiling in polycythemia vera using cDNA microarray technology. Cancer Res (2003) 63(14):3940-4.

32. Steinau M, Unger ER, Vernon SD, Jones JF, Rajeevan MS. Differentialdisplay PCR of peripheral blood for biomarker discovery in chronic fatigue syndrome. J Mol Med (Berl) (2004) 82:750-5. doi:10.1007/s00109-0040586-4

33. Werle B, Sauckel K, Nathanson CM, Bjarnadottir M, Spiess E, Ebert W, et al. Cystatins $\mathrm{C}, \mathrm{E} / \mathrm{M}$ and $\mathrm{F}$ in human pleural fluids of patients with neoplastic and inflammatory lung disorders. Biol Chem (2003) 384:281-7. doi:10.1515/ BC. 2003.031

34. Morita M, Yoshiuchi N, Arakawa H, Nishimura S. CMAP: a novel cystatin-like gene involved in liver metastasis. Cancer Res (1999) 01(59):151-8.

35. Briggs JJ, Haugen MH, Johansen HT, Riker AI, Abrahamson M, Fodstad O, et al. Cystatin E/M suppresses legumain activity and invasion of human melanoma. BMC Cancer (2010) 15(10):17. doi:10.1186/1471-2407-10-17

36. Utsunomiya T, Hara Y, Kataoka A, Morita M, Arakawa H, Mori M, et al. Cystatin-like metastasis-associated protein mRNA expression in human colorectal cancer is associated with both liver metastasis and patient survival. Clin Cancer Res (2002) 8(8):2591-4.

37. Stockmann C, Schadendorf D, Klose R, Helfrich I. The impact of the immune system on tumor: angiogenesis and vascular remodeling. Front Oncol (2014) 4:69. doi:10.3389/fonc. 2014.00069

38. Magister S, Tseng HC, Bui VT, Kos J, Jewett A. Regulation of split anergy in natural killer cells by inhibition of cathepsins $\mathrm{C}$ and $\mathrm{H}$ and cystatin $\mathrm{F}$. Oncotarget (2015) 8(6):22310-27. doi:10.18632/oncotarget.4208

39. Jewett A, Bonavida B. Target-induced anergy of natural killer cytotoxic function is restricted to the NK-target conjugate subset. Cell Immunol (1995) 160:91-7. doi:10.1016/0008-8749(95)80013-9

40. Jewett A, Bonavida B. Target-induced inactivation and cell death by apoptosis in a subset of human NK cells. J Immunol (1996) 1(156):907-15.

41. Carlsten M, Childs RW. Genetic manipulation of NK cells for cancer immunotherapy: techniques and clinical implications. Front Immunol (2015) 6:266. doi:10.3389/fimmu.2015.00266

42. Weiner MP, Costa GL. Rapid PCR site-directed mutagenesis. PCR Methods Appl (1994) 4:S131-6. doi:10.1101/gr.4.3.S131

43. Sabotic J, Bleuler-Martinez S, Renko M, Avanzo Caglic P, Kallert S, Strukelj B, et al. Structural basis of trypsin inhibition and entomotoxicity of cospin, serine protease inhibitor involved in defense of Coprinopsis cinerea fruiting bodies. J Biol Chem (2012) 3(287):3898-907. doi:10.1074/jbc.M111 285304

44. Lee BW, Olin MR, Johnson GL, Griffin RJ. In vitro and in vivo apoptosis detection using membrane permeant fluorescent-labeled inhibitors of caspases. Methods Mol Biol (2008) 414:109-35.

45. Bhat R, Watzl C. Serial killing of tumor cells by human natural killer cells - enhancement by therapeutic antibodies. PLoS One (2007) 28(2):e326. doi:10.1371/journal.pone.0000326

46. Huang C, Bi E, Hu Y, Deng W, Tian Z, Dong C, et al. A novel NF-kappaB binding site controls human granzyme B gene transcription. J Immunol (2006) 01(176):4173-81. doi:10.4049/jimmunol.176.7.4173

47. Munker R, Marini F, Jiang S, Savary C, Owen-Schaub L, Andreeff M. Expression of CD95(FAS) by gene transfer does not sensitize K562 to Fas-killing. Hematol Cell Ther (1997) 39:75-8. doi:10.1007/s00282-997-0075-7

48. Danforth DN, Zhu Y. Conversion of Fas-resistant to Fas-sensitive MCF-7 breast cancer cells by the synergistic interaction of interferon-gamma and all-trans retinoic acid. Breast Cancer Res Treat (2005) 94:81-91. doi:10.1007/ s10549-005-7491-6

49. Voskoboinik I, Thia MC, Fletcher J, Ciccone A, Browne K, Smyth MJ, et al. Calcium-dependent plasma membrane binding and cell lysis by perforin are 
mediated through its C2 domain: a critical role for aspartate residues 429, 435, 483, and 485 but not 491. J Biol Chem (2005) 04(280):8426-34. doi:10.1074/ jbc.M413303200

50. Kroemer G, Jaattela M. Lysosomes and autophagy in cell death control. Nat Rev Cancer (2005) 5:886-97. doi:10.1038/nrc1738

51. Maher K, Konjar S, Watts C, Turk B, Kopitar-Jerala N. Cystatin F regulates proteinase activity in IL-2-activated natural killer cells. Protein Pept Lett (2014) 21:957-65. doi:10.2174/0929866521666140403124146

52. Brix K, Stocker W, editors. Proteases: Structure and Function. Vienna: Springer (2013). doi:10.1007/978-3-7091-0885-7
Conflict of Interest Statement: The authors declare that the research was conducted in the absence of any commercial or financial relationships that could be construed as a potential conflict of interest.

Copyright (c) 2017 Perišric Nanut, Sabotič, Švajger, Jewett and Kos. This is an open-access article distributed under the terms of the Creative Commons Attribution License (CC BY). The use, distribution or reproduction in other forums is permitted, provided the original author(s) or licensor are credited and that the original publication in this journal is cited, in accordance with accepted academic practice. No use, distribution or reproduction is permitted which does not comply with these terms. 